\title{
Proceeding
}

Supplementary Issue: Spring Conferences of Sports Science. Costa Blanca Sports Science Events, 14-15 June 2019. Alicante, Spain.

\section{Development of methods of population's physical training by using various types of fitness based on body composition's accounting}

\author{
TATIANA SHUTOVA, TATIANA VYSOTSKAYA \\ Department of Physical Education, Plekhanov Russian University of Economics, Moscow, Russian \\ Federation
}

\begin{abstract}
Purpose: bioimpedance analysis of body composition for the different age groups of population in order to choose an individual program of physical exercise. Materials and methods: Research was done in Plekhanov Russian University of Economics (Russia, Moscow) using body composition analyzer «InBody 720» and functional diagnostics «Esteck System Complex». Research takes into account physical indicators of 359 females and 460 males from 18 to 74 years old who do not practice any physical activities or do it occasionally.Results: The study identified substantial increase in fat component of women's body in a period of $29-34$ years old $-39,6 \%$, in $46-55$ years old it is critically increasing up to $51,2 \%$. Females start feeling muscle weakness in period of 35-45 years old. In males group dynamic of fat component is on an ordinary level and even lower in a young age (18-28)-10,3\%, 29-34 years old-18\%, 35-45 years old-21,1\%, 56-74 years old-24,4\%. Most of the participants have satisfactory functional condition-70-90 points (max. 100). However, a low reaction level on an ordinary physical exertion was identified, as well as a poor level of reserved capacities of cardio-vascular and respiratory systems. Conclusion: To plan a fitness program it is necessary to consider such characteristics as age, sex, individual index of body composition and functional condition, individual preferences in types of physical exercises, indexes of hearth rate and blood pressure. While planning fitness training, it is necessary to take into account proportion between fat component and muscular component («fitness-points»), balance of energy. Keywords: Bioimpedance analysis; Functional diagnostics; Fitness program; Components of body composition; Population`s age groups.
\end{abstract}

Cite this article as:

Shutova, T., \& Vysotskaya, T. (2019). Development of methods of population's physical training by using various types of fitness based on body composition's accounting. Journal of Human Sport and Exercise, 14(4proc), S877-S884. doi:https://doi.org/10.14198//hse.2019.14.Proc4.50

Corresponding author. Department of Physical Education, Plekhanov Russian University of Economics, Stremyanny lane, 36, 117997. Moscow, Russian Federation. https://orcid.org/0000-0002-2430-0345

E-mail: golubnichaya2010@yandex.ru

Supplementary Issue: Spring Conferences of Sports Science. Costa Blanca Sports Science Events, 14-15 June 2019. Alicante, Spain.

JOURNAL OF HUMAN SPORT \& EXERCISE ISSN 1988-5202

(c) Faculty of Education. University of Alicante

doi:10.14198/jhse.2019.14.Proc4.50

VOLUME 14 | Proc4 | 2019 | $\mathbf{S 8 7 7}$ 


\section{INTRODUCTION}

Researches of human body mass have gained high importance in recent years. Results of numerous studies prove that body composition has a significant correlation with coefficient of a physical performance of a human, with his adaptation to ambient conditions, and even with his professional and sport activities (Martirosov et al., 2006; Nandalal Singn et al., 2011; Magnani Branco et al., 2015). Objective assessment of body composition allows to control human's state of health and evaluate physical condition of population (Nikolaev et al., 2009; Nikbakht et al., 2012; Jindo et al., 2016).

Bioimpedance analysis allows to evaluate efficiency and correct the training program of an athlete, predict changes in physical performance as a result of peak loads in contest season or forced decrease of physical activity after injuries and diseases. (Martirosov et al., 2006; Shevko, 2007).

Bioimpedance analysis plays a significant role in cardiovascular system and obesity diagnostics. Actually, overweight and obesity are regarded as a global problem of modern age. The reasons for this are reduction of physical activity by representatives of each age group, increasing amount of hereditary diseases, lower quality nutrition (Martins et al., 2011). Obesity is one of the most frequent chronic illness (Drenowatz, 2016; Parsons et al., 2013) and it pose a threat due to higher risk of co-existing diseases, which result in early loss of working capacity and high death rate (Vysotska et al., 2016; Krapivina, 2005; Pop, 2016). Researchers mention that $40-60 \%$ of adult population have muscle-skeleton disorder, $40 \%$ have elevated blood pressure, $25-50 \%$ of Russian population have overweight problems. Study of body composition is as relevant as ever in relation to overweight of $30-50 \%$ Russians of the first and the second middle age periods (Romanenko, 2013). These values stand at $12-15 \%$ among students (Bogdanova, 2016).

This issue has been highlighted in Government Decree N 1101-p, dated 7 Aug. 2009, "Strategy of development of physical culture and sport in Russian Federation on a period up to 2020». Government Decree highlights totality of problems in sphere of physical culture and sport. The first problem is decline of health, physical development and physical training of population. About $60 \%$ of students have health problems. It was identified in report of the Ministry of Health of Russia in 2018 that more than $65 \%$ of students have minor pathologies.

Despite the development of modern fitness technologies and wide variety of fitness programs, most of them do not based on deep understanding of biochemical mechanisms in training of population from different age groups. Furthermore, fitness programs do not consider individual characteristics of athletes, which is why they are less effective. Therefore, the most relevant methods are those that can define initial physical and functional conditions of population of different age groups. For these reasons, hardware diagnostics methods play a great role in fitness programs planning, controlling the health state of the population. They provide an opportunity to study indexes of body composition and to enhance level of physical activity.

The goal of research is a bioimpedance analysis of body composition of different age groups of the population for choosing most suitable training programs.

\section{MATERIAL AND METHODS}

\section{Participants}

359 females and 460 males from 18 to 74 years old who do not practice physical activities or do it occasionally take part in the study. Participants were divided into 5 groups by Markosyan's classification (1969):18-28 
years old - a youth age, 29-34 years old - the first middle age period, 35-55 years old -the second middle age period, 56-74 years old - an elderly age.

\section{Organization of the study}

Research was done in Plekhanov Russian University of Economics (Russia, Moscow) using body composition analyser «InBody 720» and functional diagnostics «Esteck System Complex».

\section{Statistical analysis}

For study validity, the data was processed by methods of mathematical statistics (Ivanov, 1990), by using the definition of statistical significance of mean group averages (simple arithmetic mean, standard deviation of the mean, standard error of the mean). Statistical processing of the results was done by standard software package Microsoft Excel 2007.

\section{RESULTS}

The survey reveals substantial increase of female's fat component in the first middle age period $-39,6 \%$, in $35-45$ years old $-29,6 \%$, in $46-55$ years old it is critically increased up to $51,2 \%$, in $56-74$ years old $-36,1 \%$. In addition, a big difference in fat component (\%) of females in different age periods was identified. (Figure $1)$.

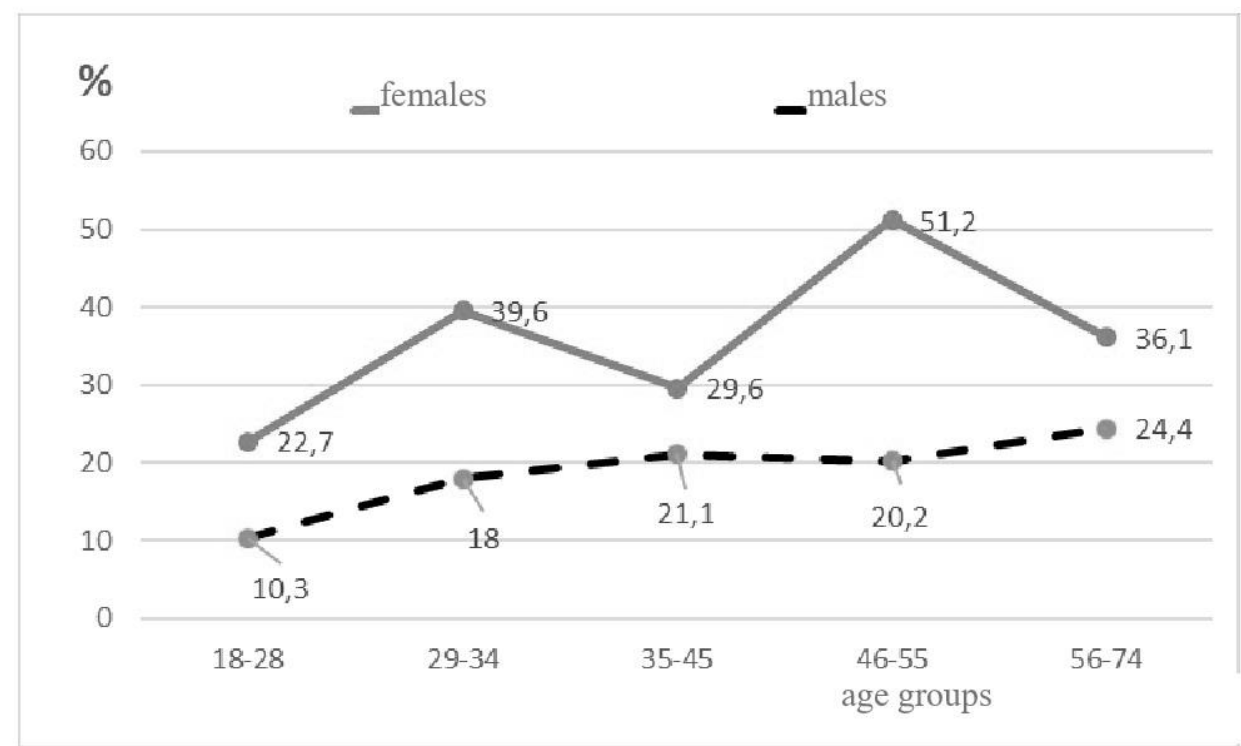

Figure 1. Fat component of males and females of different age groups.

In the first middle age period pre-obesity $(39,6 \%)$ was identified, in the second middle age period - obesity.

At the same time, male groups show lack of fat in 18-28 years old and 29-34 years old. Fat component index is on an ordinary value in other age groups. (Figure 1).

Differences in amount of extracellular water of females of different age groups (table 1) were identified, in other age groups this index is within normal limits, but it was higher than norm in the female group of 56-74 years old. By examination of «fitness points», was identified that strength and muscular component are decreasing with aging while fat component is increasing (Table 1). 
Table 1. Body composition of females of different ages

\begin{tabular}{|c|c|c|c|c|c|}
\hline $\begin{array}{c}\text { Age } \\
\text { Indicators }\end{array}$ & $\begin{array}{c}18-28 \\
\text { years old } \\
(n=96)\end{array}$ & $\begin{array}{c}29-34 \\
\text { years old } \\
(n=75)\end{array}$ & $\begin{array}{c}35-45 \\
\text { years } \\
\text { old } \\
(n=63)\end{array}$ & $\begin{array}{c}46-55 \\
\text { years } \\
\text { old } \\
(n=70)\end{array}$ & $\begin{array}{c}56-74 \\
\text { years old } \\
(n=55)\end{array}$ \\
\hline Height (cm) & $165.2 \pm 6.1$ & $164 \pm 4.9$ & $160.6 \pm 7$ & $160 \pm 7.5$ & $155.2 \pm 7.4$ \\
\hline Weight (kg) & $59.6 \pm 8.4$ & $72.3 \pm 5.4$ & $74.3 \pm 8.1$ & $86.7 \pm 6.7$ & $78.2 \pm 4.4$ \\
\hline Mass of skeletal muscles (kg) & $25.3 \pm 7.8$ & $24.1 \pm 6.5$ & $23.6 \pm 7$ & $20.1 \pm 4.3$ & $19.2 \pm 7.8$ \\
\hline Fat-free mass (kg) & $45.9 \pm 1.6$ & $43.6 \pm 2$ & $43.3 \pm 1.9$ & $42.3 \pm 2.1$ & $50.1 \pm 2.4$ \\
\hline Fat mass (kg) & $13.7 \pm 5.5$ & $28.7 \pm 5.8$ & $31 \pm 6.5$ & $44.4 \pm 7.2$ & $28.2 \pm 7.3$ \\
\hline Body fat mass (\%) & $22.7 \pm 7.2$ & $39.6 \pm 7.5$ & $29.6 \pm 8.2$ & $51.2 \pm 5.2$ & $36.1 \pm 4.9$ \\
\hline Visceral fat $\left(\mathrm{cm}^{2}\right)$ & $81 \pm 10.5$ & $82 \pm 12.1$ & $86 \pm 10.1$ & $103 \pm 9.1$ & $104 \pm 11.9$ \\
\hline Body mass ratio $\left(\mathrm{kg} / \mathrm{m}^{2}\right)$ & $22.5 \pm 3.1$ & $26.8 \pm 3.3$ & $28.2 \pm 4.1$ & $33.8 \pm 5.3$ & $33 \pm 8.9$ \\
\hline $\begin{array}{l}\text { Cellular water (1) } \\
\text { (norm: } 17-20,4 \text { liters) }\end{array}$ & $18.6 \pm 0.75$ & $22.2 \pm 0.19$ & $21.4 \pm 0.5$ & $21.5 \pm 0.9$ & $20.4 \pm 0.83$ \\
\hline $\begin{array}{l}\text { Extracellular water (l) } \\
\text { (norm: } 10,4-12,8 \text { liters) }\end{array}$ & $12.6 \pm 0.3$ & $11.9 \pm 0.5$ & $12 \pm 0.42$ & $11.8 \pm 0.6$ & $18 \pm 0.5$ \\
\hline Total water content (l) & $33.6 \pm 1.3$ & $31 \pm 1.14$ & $32.4 \pm 2.1$ & $32 \pm 1.4$ & $38.4 \pm 1.7$ \\
\hline $\begin{array}{l}\text { «Fitness-points» (correlation } \\
\text { between fat and muscular } \\
\text { components; 70-90 points - } \\
\text { norm, less than 70-muscular } \\
\text { weakness) }\end{array}$ & $79.7 \pm 6.7$ & $71.6 \pm 8.7$ & $63.1 \pm 1.5$ & $59.2 \pm 6.5$ & $47.3 \pm 3.1$ \\
\hline
\end{tabular}

Bioimpedance survey shows (Table 2) that muscular component of males dominates in structure of body composition components in every age group. Besides that, in male groups body mass index grows depending on the age, but less intensive than in female groups, in a young age index amounted to $25,3 \mathrm{~kg} / \mathrm{m} 2$, in elderly age- $27,69 \mathrm{~kg} / \mathrm{m} 2$.

Integral assessment of functional state is within normal limits in male and female in all age groups (70-90 points-satisfactory condition, 90-100 points-perfect condition). In male group of 35-45 and 46-55 years old value of functional conditions (70,4 points) is lower in comparison with elderly group of males and females (72,9-76,3 points). 
Heart rate of young people (18-28 years old) accounts for $85,5-93,1$ beat per minute (males and females), this is the highest mark of all age groups (73,0-79,2 bpm in middle age and elderly age groups).

Table 2. Body composition of males of different ages

\begin{tabular}{|c|c|c|c|c|c|}
\hline $\begin{array}{c}\text { Age } \\
\text { Indicators }\end{array}$ & $\begin{array}{c}18-28 \\
\text { years old } \\
(n=217)\end{array}$ & $\begin{array}{c}29-34 \\
\text { years old } \\
(n=62)\end{array}$ & $\begin{array}{l}35-45 \\
\text { years old } \\
(n=62)\end{array}$ & $\begin{array}{c}46-55 \\
\text { years old } \\
(n=64)\end{array}$ & $\begin{array}{c}56-74 \\
\text { years } \\
\text { old } \\
(n=55)\end{array}$ \\
\hline Height (cm) & $175.2 \pm 8.8$ & $175.3 \pm 6.7$ & $174.9 \pm 7.8$ & $172.9 \pm 8.4$ & $171 \pm 5.5$ \\
\hline Weight (kg) & $77.9 \pm 7.6$ & $78.3 \pm 6.1$ & $77.4 \pm 5.1$ & $75.7 \pm 5.7$ & $74.8 \pm 5.6$ \\
\hline Mass of skeletal muscles (kg) & $35.7 \pm 5.7$ & $36.1 \pm 3.1$ & $36.3 \pm 4.3$ & $35.4 \pm 4.7$ & $33.3 \pm 3.7$ \\
\hline Fat-free mass (kg) & $62.5 \pm 9.3$ & $63.9 \pm 7.5$ & $64.1 \pm 7.5$ & $62.7 \pm 8.1$ & $60 \pm 9.3$ \\
\hline Fat mass (kg) & $7.5 \pm 5.1$ & $14.4 \pm 6.3$ & $17.8 \pm 8.7$ & $17.5 \pm 10.3$ & $19.8 \pm 7.7$ \\
\hline Body fat mass (\%) & $10.3 \pm 5.7$ & $18 \pm 6.9$ & $21.1 \pm 8.4$ & $20.8 \pm 8.3$ & $24.4 \pm 5.4$ \\
\hline Visceral fat $\left(\mathrm{cm}^{2}\right)$ & $80 \pm 7.5$ & $90.1 \pm 10$ & $93.1 \pm 8.1$ & $91 \pm 10$ & $93.2 \pm 8.9$ \\
\hline Body mass ratio $\left(\mathrm{kg} / \mathrm{m}^{2}\right)$ & $25.3 \pm 3.1$ & $25.5 \pm 2.6$ & $25.2+3.5$ & $25.3 \pm 4.7$ & $27 \pm 3.9$ \\
\hline Cellular water (l) & $28.9 \pm 2.2$ & $29 \pm 2.3$ & $29.1 \pm 2.3$ & $28 \pm 2.1$ & $27.7 \pm 3$ \\
\hline Extracellular water (1) & $16.7 \pm 1.3$ & $17.3 \pm 2$ & $17.4 \pm 2.1$ & $17.4 \pm 2.3$ & $17.9 \pm 2.4$ \\
\hline Total water content (1) & $45.8 \pm 9.4$ & $46.8 \pm 5.5$ & $47.1 \pm 5.5$ & $46.2 \pm 6.1$ & $43.1 \pm 5.1$ \\
\hline $\begin{array}{l}\text { «Fitness-points» (correlation } \\
\text { between fat and muscular } \\
\text { components, } 70-90 \text { points - } \\
\text { norm, less than } 70 \text {-muscular } \\
\text { weakness) }\end{array}$ & $82.3 \pm 9.1$ & $80.5 \pm 6.1$ & $79.3 \pm 5.8$ & $79.6 \pm 7.4$ & $74.6 \pm 6.6$ \\
\hline
\end{tabular}

\section{DISCUSSION}

Studies show that significant increase in fat component of the body appears in the first middle age period (29-34 years old), this is the most beneficial period of metabolic processes. That is why study of body composition is important even in a youth and first middle age period. (Zhou, 2019; Georgesen, 2014; Suadicani et al.,2005). 
Researches in sphere of sport and recreation conducted by Department of Culture, Media and Sport in England involve a questionnaire for adults and young people (92000interview). The survey has identified the most popular athletic disciplines for males and females: swimming, recreative fitness and cycling. According to these facts, world academic community started reforming the fitness programs, making them more effective by considering components of body composition (Roy et al., 2017; Ortega et al., 2015; Hoye et al., 2014; Gibbs et al., 2012; Schumann et al., 2002).

\section{CONCLUSION}

To plan a fitness program it is necessary to consider such characteristics as age, sex, individual index of body composition and functional condition, individual preferences in types of physical exercises, indexes of hearth rate and blood pressure. While planning fitness training, it is necessary to take into account a proportion between fat component and muscular component («fitness-points»), balance of energy. Moreover, it is necessary to make a list of preferable food, calculate the necessary number of calories per day for each athlete.

Females at the age of 29-34 have normal amount of "fitness-points», 35-74 years old females -below normal. The study reveals substantial increase of female's fat component in first the middle age period $-39,6 \%$, in 46-55 years old it's critically increases up to $51,2 \%$. The volume of extracellular water remains at the same level in all female age groups. High values of female's fat component, lack of permanent physical exercises and pain in the spinal column require females to do water fitness. Water fitness in a swimming pool is recommended for women with obesity, varicose veins, osteochondrosis, elevated or low blood pressure, arthropathy, neurosis, hypodynamia, post-trauma recovery, vertebral disc prolapse, hypomyotonia, and disability of doing physical exercises of high-intensity out of water. Fitness programs for women should be chosen in such a way to consider the necessity of increasing aerobic activity of low intensity and importance of decreasing of fat components. Such fitness programs as artistic gymnastics, water aerobics, pilates, water jogging and aerobics are recommended for females at the age of 35-45. Women at the age of 46-55 should choose water program «Swimming and Power», water jogging, stretching, walking on a treadmill and Nordic walking.

Level of male's physical condition is much better than in female groups, this relates to such indicators as «fitness-points», extracellular water and minerals. In males group dynamic of fat component is on an ordinary level and even lower in a young age (18-28)-10,3\%, 29-34 years old-18\%, 35-45 years old-21,1\%, 56-74 years old-24,4\%. The most suitable fitness programs for males are swimming, jogging, artistic gymnastics, functional training with control of hearth rate, mixed fitness programs with low intensity. While fitness programs planning for males of the first and second middle age groups it is preferable to use jogging with low or middle intensity, recreational artistic gymnastics, swimming, game-oriented sports and walking with steps counting.

It is recommended to use mobile applications with daily steps calculation such as «Zdorovie», «Stepz».

\section{CONFLICT OF INTEREST}

Authors state that there is no conflict of interest. 


\section{REFERENCES}

Bochkareva, S.I., Buyanova T.V., Vysotskaya T.P., \& Golubnichiy S.P. (2018). Online education resources applied in academic physical education process. Theory and Practice of Physical Culture, $3,15$.

Bogdanova, N.S. (2016). The problem of obesity and physical activity. Science - 2020, 2(8), 120-125. [in Russian].

Branco, B.H.M., Massuca, L.M., Pagan, B.G.M., Cremon, A.D.S., Andreatoa, L.V., Miarka, B., \& Fragoso, I. (2015). Impact of body composition and physiological responses at half race to predict $10.000 \mathrm{~m}$ recreational road race. Journal of Physical Education and Sport, 15(1), 3-8. https://doi.org/10.7752/jpes.2015.01001

Drenowatz, C. (2016). The Obesities: Various Paradigms Addressing a Single Problem. American Journal of Lifestyle Medicine, 10(2), 97-99. https://doi.org/10.1177/1559827615618877

Fritz, N.B., Gargallo, P., Calatayud, J., Fernandez-Garrido, J., Rogres, M.E., \& Colado, J.C. (2018). Positive Effects of a Short-Term Intense Elastic Resistance Training Program on Body Composition and Physical Functioning in Overweight Older Women. Biological Research For Nursing, 3(20), 321334. https://doi.org/10.1177/1099800418757676

Georgesen, S.E. (2014). The Complex Problem of Childhood Obesity. Western Journal of Nursing Research, 36(5), 579-580. https://doi.org/10.1177/0193945914525353

Gibbs, B.B., Brancati, F.L., Chen, H., Coday, M., Jakicic, J.M., Lewis, C.E., ... Clark, J.M. (2014). Effect of improved fitness beyond weight loss on cardiovascular risk factors in individuals with type 2 diabetes in the Look AHEAD study. European Journal of Preventive Cardiology, 21(5), 608-617. https://doi.org/10.1177/2047487312462823

Jindo,T., Fujii, K., Tsunoda, K., Fujii, Y., Sriramatr, S., \& Okura. T. (2016). Effect of increased daily physical activity on lower-extremity physical function during an exercise program for older adults. Journal of Physical Education and Sport, 16(3), 816-822. https://doi.org/10.1249/01.mss.0000485380.95433.b1

Krapivina, N.A. (2005). Optimization of treatment of obesity in women of reproductive age (dissertation). Tomsk: Siberian state medical University [in Russian].

Martirosov, E.G., Nikolaev, D.V., \& Rudnev, S.G. (2006). Technologies and methods of human body composition assessment. Moscow: Nauka [in Russian]. http://www.inm.ras.ru/library/Rudnev/book2006.pdf

Martins, J.C., Marialva, A.F., Afonso, M., Gameiro, N.F., \& Costa, A.M. (2011). Effects of an 8-week physical activity program on body composition and physical fitness on obese and pre obese female students. Journal of Physical Education and Sport, 11(2), 226-234. http://www.efsupit.ro/images/stories/21 J.pdf

Nandalal Singh, N.D., Ranjit Singh, R., \& Kumar Singh, S.V. (2011). Study of trunk flexibility and body composition between football and badminton players. Journal of Physical Education and Sport, 11(1), 18-21. $\quad$ http://www.efsupit.ro/images/stories/imgs/JPES/2011/1/microsoft\%20word\%20\%202\%20macheta.pdf

Nikbakht, M., Ghanbarzadeh, M., \& Tafah, M. (2012). Comparing effect of intense and moderate exercise on aerobic fitness \& body composition of overweight 9-12 years old boys. Journal of Physical Education and Sport, 12(2), 230-233. http://www.efsupit.ro/images/stories/vol_12_2 Art_35.pdf

Nikolaev, D.V., Smirnov, A.V., Bobrinskaya, I.G., \& Rudnev, S.G. (2009). Bioimpedance analysis of human body composition. Moscow: Nauka [in Russian]. http://window.edu.ru/resource/030/73030/files/book2009.pdf 
Ortega, F.B., \& Ruiz, J.R. (2015). Fitness in Youth: Methodological Issues and Understanding of Its Clinical Value. American Journal of Lifestyle Medicine, 9(6), 403-408. https://doi.org/10.1177/1559827615598531

Parsons, W.G., Garcia, G.M., \& Hoffman, P.K. (2014). Evaluating School Wellness Policy in Curbing Childhood Obesity in Anchorage, Alaska. The Journal of School Nursing, 30(5), 324-331. https://doi.org/10.1177/1059840513513155

Pop, C.L. (2016). Risk assessment of overweight and obesity by two methods with different results. Physical Education of Students, 20(3), 53-57. https://doi.org/10.15561/20755279.2016.0306

Roy, B., Roberts, P., Lisowski, C., Kaye, M.P., \& Sforzo, G.A. (2017). Integrating Health Coaching With a Medical Fitness Program to Treat Chronic Health Conditions. American Journal of Lifestyle Medicine. https://doi.org/10.1177/1559827617728025

Romanenko, N.I. (2013). The content of physical training of women 35-45 years using different types of fitness based on somatotype (dissertation). Krasnodar: Kuban state University physical culture, sporta and tourism [in Russian]

Schumann, A., Nigg, C.R., Rossi, J.S., Jordan, P.J., Norman, G.J., Garber, C.E., ... Benisovich, S.V. (2002). Construct Validity of the Stages of Change of Exercise Adoption for Different Intensities of Physical Activity in Four Samples of Differing Age Groups. American Journal of Health Promotion, 16(5), 280-287. https://doi.org/10.4278/0890-1171-16.5.280

Shevko, N.B. (2007). Analysis of the dynamics of the main bioimpedance parameters of sportsmen body composition. Health and Environmental Issues, 2(12), 101-105. [in Russian].

Shutova, T.N., Vysotskaya, T.P., Bodrov, I.M., \& Rybakova, E.O. (2018). Program for the modernization of preparation of physical cultural bachelors in the field of recreation. Journal of Physical Education and Sport, 18, 1130-1135. https://doi.org/10.7752/jpes.2018.s2168

Suadicani, P., OleHein, H., \& Gyntelberg, F. (2005). Lifestyle, social class, and obesity-the Copenhagen Male Study. European Journal of Cardiovascular Prevention \& Rehabilitation, 12(3), 236-242. https://doi.org/10.1097/01.hir.0000160600.64633.6f

Van Hoye, A., Sarrazin, P., Heuzé, J.-P., \& Kokko, S. (2015). Coaches' perceptions of French sports clubs: Health-promotion activities, aims and coach motivation. Health Education Journal, 74(2), 231243. https://doi.org/10.1177/0017896914531510

Vysotska, O., Dobrorodnia, G., Gordienko, N., Klimenko. V., Chovpan, G., \& Georgiyants, M. (2016). Investigation of the mechanisms of formation and development of overweight and obesity for the information system of diagnostics of obesity. Eastern-European Journal of Enterprise Technologies, 2(84), 15-23. https://doi.org/10.15587/1729-4061.2016.85390

Zhou, M. (2019). The shifting burden of obesity: Changes in the distribution of obesity in China, 20102015. International Sociology. https://doi.org/10.1177/0268580919832734

\section{(9) $\Theta \Theta(\Theta$}

This work is licensed under a Attribution-NonCommercial-NoDerivatives 4.0 International (CC BY-NC-ND 4.0). 